\title{
Investigation of subsurface fatigue crack in PEEK shaft under one-point rolling contact by using 2.5D layer observation method
}

\author{
Hitonobu KOIKE ${ }^{1 a}$, Genya YAMAGUCHI ${ }^{2}$, Koshiro MIZOBE ${ }^{2}$, Yuji KASHIMA ${ }^{3}$, and Katsuyuki KIDA² \\ ${ }^{1}$ Kyushu Sangyo University, 2-3-1, Matsukadai, Higashi-ku, Fukuoka, 813-8503, Japan \\ ${ }^{2}$ University of Toyama Gofuku 3190, Toyama, 930-8555, Japan \\ ${ }^{3}$ Kashima bearings Inc. 2-9-21 Himesato Nishi-Yodogawa-ku Osaka, 555-0025, Japan
}

\begin{abstract}
Subsurface fatigue cracks under rolling contact area of the PEEK shaft against an alumina bearing's ball were investigated for application of frictional part in mechanical element in special situations such as chemical environments. In order to explore the flaking process of the PEEK shaft, the rolling contact fatigue tests were carried out by using a one-point radial loading rolling contact machine. The flaking occurred on the rolling track of the PEEK shaft at approximate $4 \times 10^{5}$ fatigue cycles. The subsurface fatigue crack propagation was investigated by using 2.5-Dimension layer observation method. The flaking was caused by the propagations of surface cracks and subsurface shear cracks, and the flaking shape was half-ellipse. Moreover, beach marks as fatigue crack propagation in the flaking were observed.
\end{abstract}

\section{Introduction}

Lightweight function parts using premium plastic are extended in various mechanical elements under special situation such as chemical, medical, space or flying devices [1-2]. Poly-ether-ether-ketone (PEEK), which is semi-crystalline polymer containing phenyl and ketone groups, has high corrosion resistance, self-lubrication ability, low specific gravity, high impact durability, and high melting temperature of $340^{\circ} \mathrm{C}$. Therefore PEEK is one of the most promising materials for precisionmachined custom bearing or gear etc. Researchers investigated tribological failures of PEEK materials for frictional parts [3-6]. Dearn et al. reported that the location of the maximum shear stress depends on the friction condition and is related with the fracture of PEEK polymer gears [3]. Hoskins et al. stated that in the PEEK twin disc test, failure including melting was observed on the contact surfaces in severe high slip-ratio, high load conditions [4]. Harras et al. stated that in rolling wear test, the heat accumulated inside of the material due to cyclic revolutions is too high because of the polymer's low thermal conductivity. As a result, the material starts softening [5]. Fridrich et al. investigated various failure patterns through their works. They stated that Mode I fatigue was not the dominant mechanism from results of the brock on ring wear tests of PEEKs with different molecular weight against hard steels [6]. The PEEK's tribological fatigue flacture mechanism is not well understood.

Meanwhile, the practical application research on PEEK's tribological fatigue fracture of the combination

\footnotetext{
a Corresponding author: koike@ip.kyusan-u.ac.jp
}

between PEEK plastic and ceramic part is only few studies [7-9]. In the previous study, we reported that the subsurface crack propagated along the PEEK shaft rolling direction in terms of fatigue failure mechanism when cyclic compressive stress was applied to the PEEK shaft [9].

In this study, the PEEK shafts were manufactured by machining for practical applications. The one-point loading rolling contact fatigue (one-point RCF) tests under an oil lubricant condition were performed, in order to explore the subsurface fatigue crack and flaking failure mechanism of the PEEK shaft against an alumina ball.

\section{Experimental Procedure}

\subsection{PEEK shaft}

Figure 1 shows the PEEK shaft specimen for the onepoint radial loading rolling contact fatigue (RCF) test. Table 1 shows the grade and dimensions of the machined PEEK shaft for the one-point RCF test. The PEEK material grade was $450 \mathrm{G}$ in VICTREX ${ }^{\mathrm{TM}}$. Young's modulus and Poisson's ratio of PEEK were $3.5 \mathrm{GPa}$ and 0.4 , respectively. The PEEK shaft specimens were made through a lathe maching and a griding. After the grinding process on the PEEK shafts, the average roughness $\left(R_{a}\right)$ 
on the surface of the shaft were $0.69 \sim 1.10 \mu \mathrm{m}$ (Maximum

height roughness $\left.R_{z}=4.81 \sim 5.74 \mu \mathrm{m}\right)$.

Table 1. The machined PEEK shaft specimen.

\begin{tabular}{|c|c|c|c|c|c|}
\hline Grade & $\begin{array}{c}\text { Young's } \\
\text { modulus, GPa }\end{array}$ & $\begin{array}{c}\text { Length, } \\
\mathbf{m m}\end{array}$ & Diameter, $\mathbf{m m}$ & $\boldsymbol{R}_{\boldsymbol{a}}, \boldsymbol{\mu \mathbf { m }}$ & $\boldsymbol{R}_{\boldsymbol{z}}, \boldsymbol{\mu m}$ \\
\hline $450 \mathrm{G}$ & 3.5 & 290 & 17 & $0.69-1.10$ & $4.81-5.74$ \\
\hline
\end{tabular}
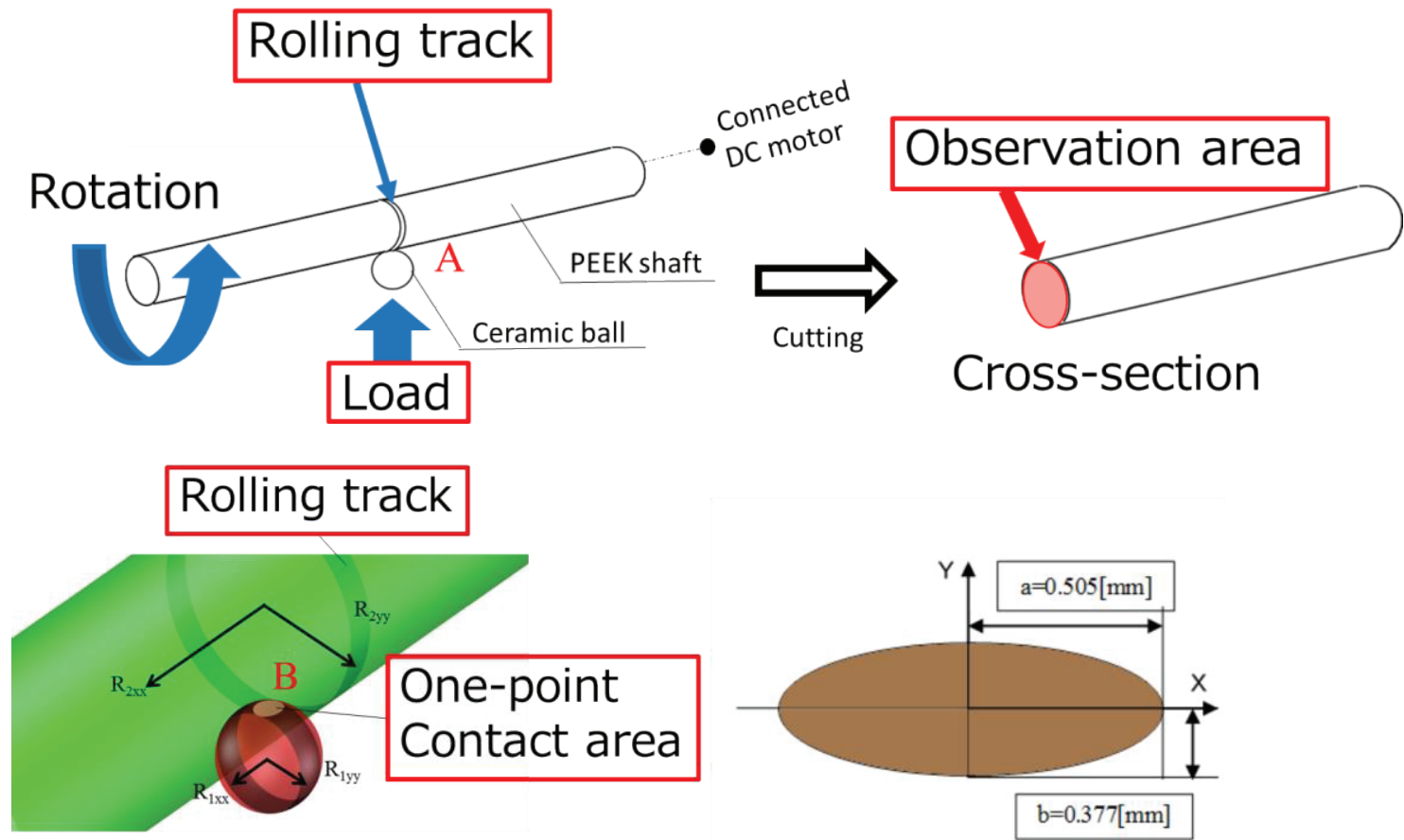

Detail A. Rolling track

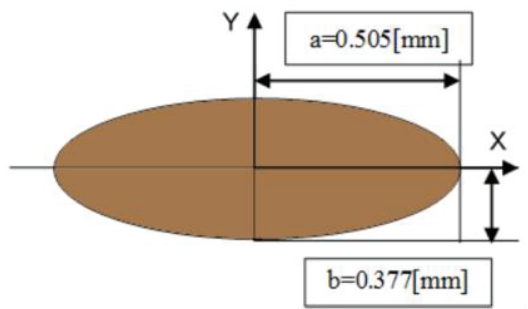

Detail B. Hertzian contact area

Fig. 1. Dimension and testing position of PEEK shaft specimen in one-point loading RCF. Note that $X$ axis represents axial direction.

\subsection{One-point rolling contact fatigue test}

The RCF tests were carried out with the one-point radial loading machine (Yosinori industry Ltd.) under oil lubricant condition [10]. The VG46 lubricant oil was used. A shown in Figure 1, one alumina ball with 9.52 mm diameter contacted the PEEK shaft surface. $120 \mathrm{~N}$ radial load was applied to the PEEK shaft. The advantage of the one-point RCF testing is efficient observation. Whole subsurface under the rolling track of the shaft specimen can be observed continuously. Thus, fatigue fracture mechanism by rolling contact can be investigated easily. The contact was Hertzian point contact as shown in Detail B of Figure 1. The size of the contact area was $' \mathrm{a} '=0.505 \mathrm{~mm}$ and $' \mathrm{~b} '=0.377 \mathrm{~mm}$. The maximum Hertzian contact stress on the contact area between the PEEK shaft and the alumina ball was $301 \mathrm{MPa}$ from Hertzian theory. The RCF test speed was $1200 \mathrm{rpm}$. The rolling track can be concentrated only one line under a radial load as shown in Detail A of Figure 1. The onepoint RCF tests were continued until fatigue failure. The PEEK shaft after the test was cut along the rolling track, in order to observe the subsurface of the PEEK shaft. The cross-sections of the PEEK shaft were polished by diamond suspension. The subsurface fatigue cracks on the cross-sections of the PEEK shaft were observed by laser confocal microscopy (LCM). The maximum crack

depths of the subsurface fatigue cracks were measured by the LCM.

\section{Experimental results and discussion}

\subsection{Fatigue fracture of PEEK shaft under rolling contact}

Figure 2 shows the microscope image of the fatigue fracture on the rolling track of the PEEK shaft after the tests. A flaking as fatigue fracture occurred on the rolling track at $4.1 \times 10^{5}$ fatigue cycles. The maximum lengths of the flaking toward rolling direction and axial direction were approximately 2000 and $1400 \mu \mathrm{m}$, respectively. The rolling track of the PEEK shaft was little worn. Figures 3 shows the 2D-contour line of maximum crack depths of the flaking of the PEEK shaft. The dot-break line at $0 \mu \mathrm{m}$ represents the CTR line in Figure 2. The $X$ axis, the axial direction of the PEEK shaft, represents the distance from the CTR line. The points of black solid circle with numbers correspond to the layer numbers of the LCM images in Figures 4. At measurement point CTR (Layer \#8), the maximum crack depth was $352 \mu \mathrm{m}$ as the $1 \mathrm{st}$ 
flaking bottom. The maximum crack depth depended on the distribution of maximum shear stress $\left(\tau_{x z}\right)$ under Hertzian contact. In the axial direction, the maximum crack depths around $0 \sim 375 \mu \mathrm{m}$ distance were approximately $350 \mu \mathrm{m}$. The internal shear crack occurred at this maximum crack depth of plateau zone due to $\tau_{x z}$. The maximum crack depths around $375 \sim 825 \mu \mathrm{m}$ distance in the axial direction was deeper than that of the 1st flaking. This observation results show the multiflaking occurrence.

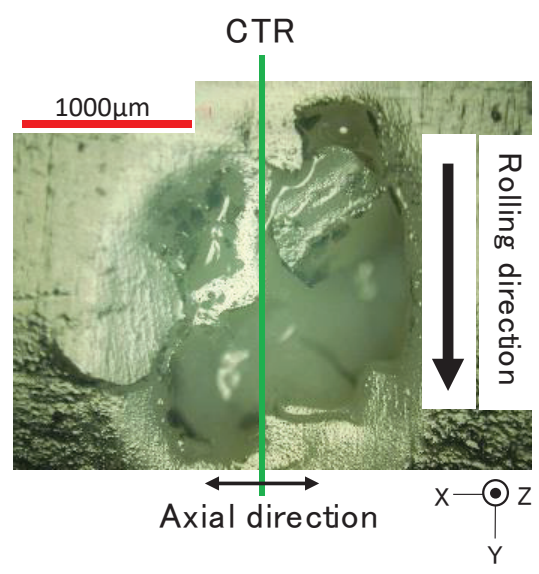

Fig. 2. Microscope image of flaking failure.

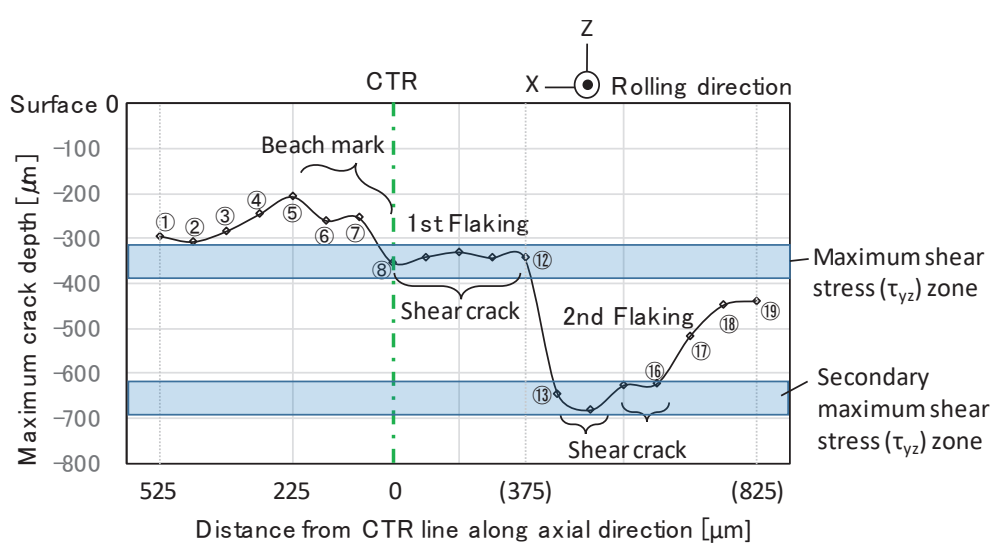

Fig. 3. Maximum crack depth from surface in the flaking area.
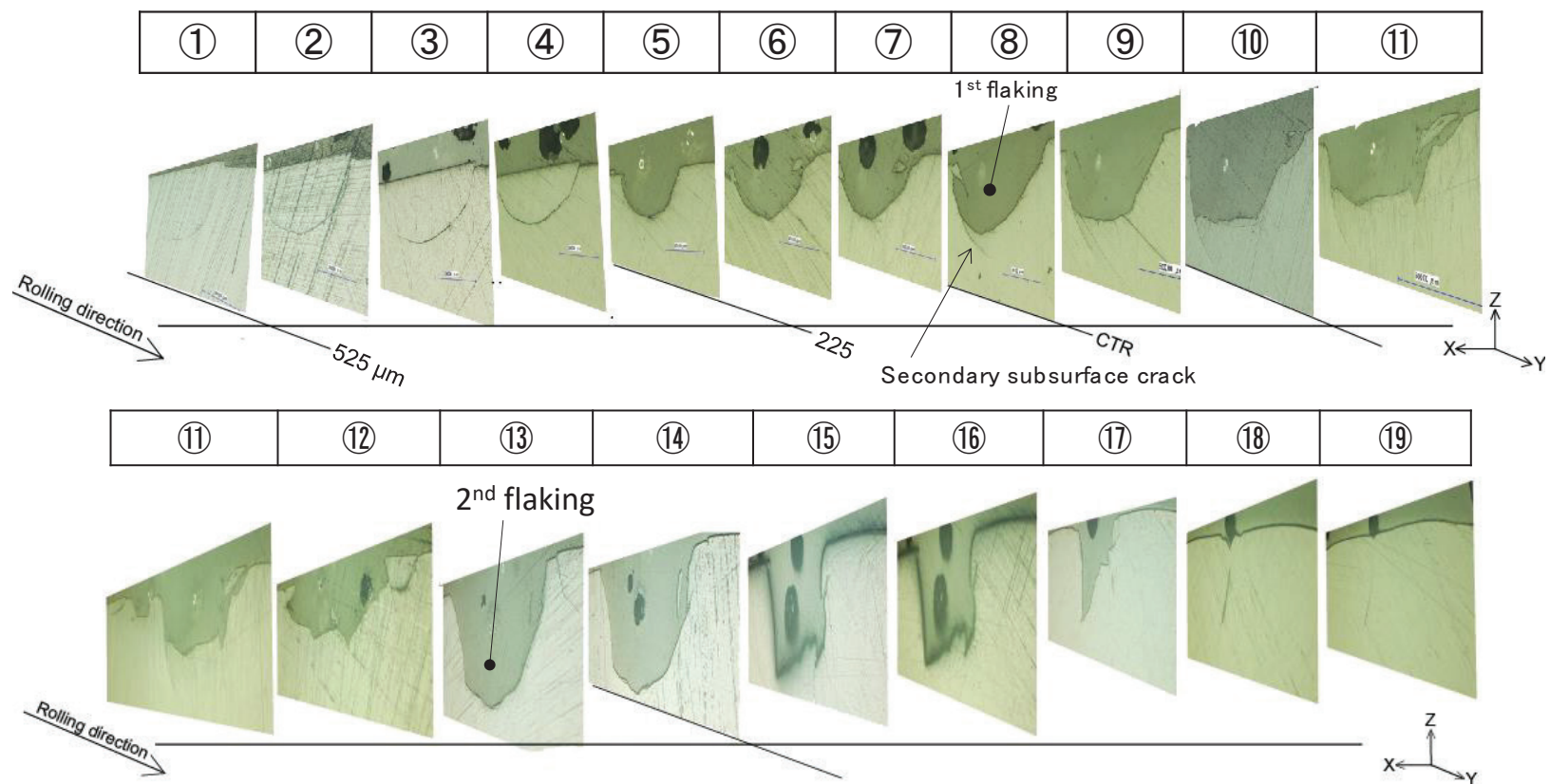

Fig. 4. Microscope images of 2.5D layer of the PEEK shaft subsurface.
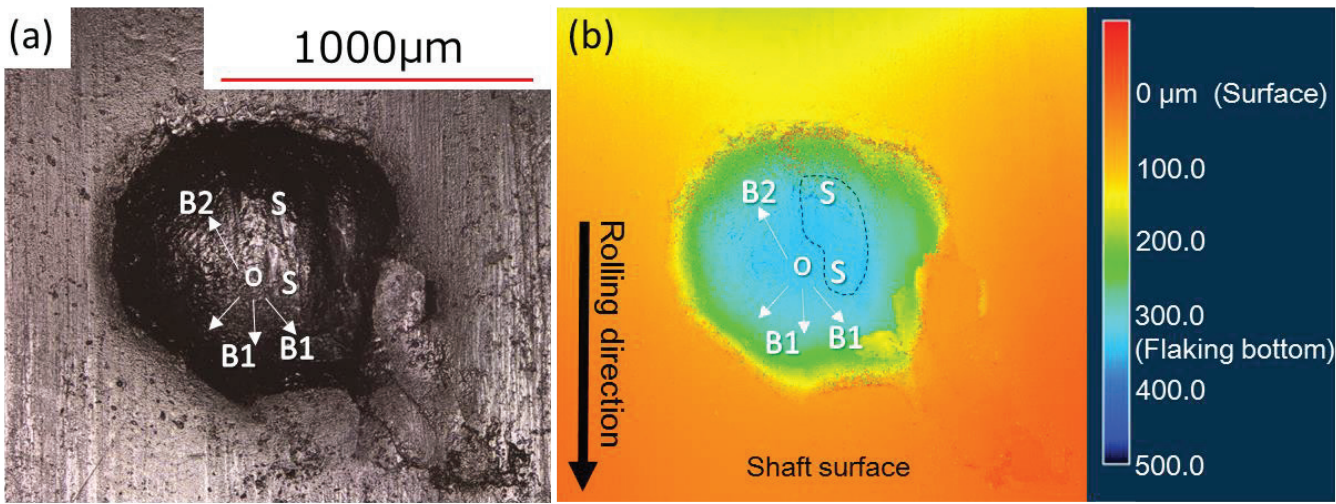

Fig. 5. LCM image of the flaking; (a) laser image and (b) contour image. Note that ' $O$ ' represents crack initiation point, ' $B$ ' means beachmark and crack's direction, and ' $S$ ' means shear crack. 


\subsection{Subsurface crack propagation}

Figure 4 shows the LCM images of 2.5D layer of the shaft subsurface. The distance between layers was $75 \mu \mathrm{m}$. The layer image (Layer \#8) corresponds to the crosssection at CTR position in Fig. 2. The maximum crack depth in layer \#8 was $352 \mu \mathrm{m}$. In the previous work, we reported that the subsurface crack propagated along the PEEK shaft rolling direction [9]. After that, the subsurface crack direction changed toward the shaft surface. From this work, it was found that the subsurface crack also propagated toward the axial direction and shaft surface. Moreover, in the layer images (Layer \#9-12), the secondary subsurface crack was observed at the bottom of the 1st flaking. It was thought that the secondary subsurface fatigue crack influenced the secondary flaking occurance as shown in Layer \#13. The flakings grew gradually due to complex subsurface fatigue crack propagation. Figures $5 \mathrm{a}$ and $5 \mathrm{~b}$ show the LCM image and the contour image of the flaking after $4.6 \times 10^{5}$ fatigue cycles, respectively. The fracture with plastic deformation was localy observed on the S-S area in Figure 5a. The depth at the S-S area was measured approximately $300 \mu \mathrm{m}$ from the shaft surface as shown in Figure 5b. This means that the shear crack occurred in the subsurface around $300 \mu \mathrm{m}$ depth due to compressive and shear stresses. Beach mark indicating internal fatigue cracks was observed at ' $\mathrm{B}$ ' point in Fig. 5a. The beach mark was located in the blue-green color area in Figure $5 \mathrm{~b}$. The subsurface crack direction changed in this area. The beach mark was influenced by cyclic tensile crack rather than shear crack. This means that the subsurface fatigue crack propageted toward radial direction from bottom (' $\mathrm{O}$ ' point) to the shaft surface. In the beach marks at $\mathrm{B} 1$ and $\mathrm{B} 2$ points, the subsurface fatigue crack propagation rates in the rolling direction (B1) and the opposite direction (B2) were different as seen in the beach mark stripe's width. These resluts show that the fatigue crack propagation rate difference influenced the flaking occurrance time and the flaking shape. The mechanism of subsurface fatigue crack is discussed following; Firstly, the subsurface fatigue crack ocuured due to shear stress. Then, the subsurface fatigue crack propageted toward radial direction, and changed crack direction. The flaking shape was half-ellipse.

This research work is financial supported by JSPS KAKENHI Grant Number JP16K06042. A part of this work was supported by JKA and its promotion funds from KEIRIN RACE (No. 27-124, 28-138).

\section{Conclusions}

In order to explore the flaking process of the PEEK shaft against an alumina bearing's ball, the one-point radial loading rolling contact fatigue tests were carried out. The important results obtained from this work can be summarized as follows:
(1) Subsurface shear crack as Mode II fatigue was caused by maximam shear stress at $352 \mu \mathrm{m}$ depth from the shaft surface.

(2) Beach mark as Mode I fatigue crack propagation was observed locally in the flaking. This area was corresponded to the zone where the subsurface crack propagation direction changed.

(3) From the reasons above (1) and (2), the subsurface fatigue crack propagated toward the rolling and axial direction.

\section{References}

1. T. A. Stolarski, Adv. Comp. Trib.edited by K. Friedrich, Elservier, Chapter 17, (1993).

2. K. Friedrich, G. Theiler and P. Klein, In: SinhaSK, BriscoeBJ, editors. Polymer Tribology, London UK: Imperial College Press, 375-415, (2009).

3. K. D. Dearn, S. N. Kukureka, and D. Walton, In: SinhaSK, BriscoeBJ, editors. Polymer Tribology. London UK: Imperial College Press; 470-505, (2009).

4. T. J. Hoskins, K. D. Dearn, Y. K. Chen, and S. N. Kukureka, Wear, 309, 35-42, (2014).

5. K. Friedrich, Z. Lu and A. M. Häger, Theoretical and Appl. Frac. Mech., 19, 1-11, (1993).

6. M. Harrass, K. Friedrich, and A. A. Almajid, Trib. Int'1, 43, 635-646, (2010).

7. H. Koike, K. Kida, T. Honda, K. Mizobe, S. Oyama, J. Rozwadowska, Y. Kashima, and K. Kanemasu, Adv. Mat. Res., 566, 109-114, (2012).

8. H. Koike, K. Kida, E. C. Santos, J. Rozwadowska, Y. Kashima and K. Kanemasu, Trib. Int'1, 49, 30-38, (2012).

9. H. Koike, G. Yamaguchi, K. Mizobe, Y. Kashima, and K. Kida, Mat. Sci. Forum, 878, 137-141, (2017).

10. S. Hazeyama, J. Rozwadowska, K. Kida, E. C. Santos, T. Honda, K. Kanemasu, and T. Shibukawa, Adv. Mat. Res., 566, 182-186, (2012). 